\title{
DA DISCÓRDIA À SOLUÇÃO ADEQUADA DE CONTROVÉRSIAS: A BUSCA POR MECANISMOS ALTERNATIVOS PARA SATISFAÇÃO ENTRE AS PARTES CONFLITANTES
}

\section{FROM DISCOURSE TO THE ADEQUATE SOLUTION OF CONTROVERSIES: A SEARCH FOR ALTERNATIVE MECHANISMS FOR SATISFACTION BETWEEN CONFOUNDING PARTIES}

\section{MAURO DE PAULA BRANCO}

Mestrando do Programa de Mestrado em Direito Empresarial e Cidadania do Centro Universitário Curitiba (UNICURITIBA).

\section{RESUMO}

O presente artigo científico possui como objetivo demonstrar ao leitor a maneira como as relações processuais são, ao longo da história, tratadas dentro do Direito e como é possível proporcionar mecanismos diversos para a solução alternativa de conflitos. Para tanto, dentro de uma análise epistemológica, a qual se vale do racionalismo para demonstrar quais as possíveis maneiras de se chegar a consensos válidos, judicial ou extrajudicialmente. O método pretendido é o indutivo, levando o interprete a entender quais as possibilidades de se adentrar em uma relação contenciosa, mas que pode se resolver consensualmente.

PALAVRAS-CHAVE: Controvérsias; Positivismo Jurídico; Satisfação; Autocomposição; Soluções Alternativas; Mediação; Conciliação; Métodos Adequados. 


\section{Personalidade Acadêmica Homenageada:}

Florisbal de Souza Del'Olmo (Professor Convidado - UNICURITIBA)

\section{ABSTRACT}

This article aims to demonstrate to the reader the way in which procedural relationships are dealt with within the Law and how it is possible to provide diverse mechanisms for alternative dispute resolution. To do so, within an epistemological analysis, which uses rationalism to demonstrate the possible ways to reach valid consensus, judicially or extrajudicially. The intended method is the inductive, leading the interpreter to understand the possibilities of entering into a contentious relationship, but that can be resolved consensually.

KEYWORDS: Controversies; Legal Positivism; Satisfaction; Self; Composition; Alternative Solutions; Mediation; Conciliation; Appropriate Methods.

\section{INTRODUÇÃO}

É compreensível que qualquer intérprete, sobretudo aos pouco familiarizados com o tema aqui desenvolvido, leve à mente, quando se depara com a expressão "direito processual", a ideia de conflito, pois automaticamente a tendência é que se vincule qualquer conflito à existência de lide. $E$ assim a doutrina, e mesmo a preparação acadêmica dos operadores do Direito, vêm formando os novos profissionais do universo jurídico há tempos, não querendo dizer que esta interpretação se restrinja a estes, quando na verdade a própria coletividade crê na concepção de disputa dentro de qualquer resolução processual. No entanto, o que se tem notado é que há um crescente movimento rumo a outras alternativas para a solução de controvérsias. As chamadas Resoluções Alternativas de Disputas são uma resposta ao anseio, mesmo que inconsciente de grande parte da sociedade, para a busca de novos meios de satisfação da vontade dos indivíduos que à compõem. O diálogo colaborativo tem sido um dos mais importantes mecanismos de harmonização de conflitos, estando presente em todas as técnicas de solução de controvérsias e disputas, trazendo o consenso à tona em resposta ao grande 


\section{Personalidade Acadêmica Homenageada:}

Florisbal de Souza Del'Olmo (Professor Convidado - UNICURITIBA)

desgaste das disputas contenciosas, diante das quais, embora haja uma parte que sucumba e outra que vê os seus pedidos conhecidos, não surgem vitoriosos.

Assim sendo, a proposta deste artigo é expandir a consciência em direção aos novos tempos, contando para isso com a colaboração não só das partes envolvidas na controvérsia, mas também com os operadores do Direito e outros profissionais que tenham a mesma visão de rompimento com a lide como condição necessária para o andamento processual, pois em muitas vezes esta pode ser evitada. E por que não fazer?

Dessa forma, o convite é para que todos olhem com especial atenção a todas as tendências de resolução adequada das controvérsias, não sem antes buscar entender como estas ocorrem e onde se manifestam para além do mundo jurídico.

\section{ENTRE A NECESSIDADE DA DESAVENÇA E A POSSIBILIDADE DA AUTOCOMPOSIÇÃO}

Marco Aurélio, senhor do mundo antigo, um dia ensinou que "a alma de um homem maltrata a si própria quando despreza outro homem, ou procura lhe fazer mal por raiva" (HICKS e HICKS, 2007. p. 52). Com essas palavras, o imperador romano deixou pistas de que a relação entre os indivíduos se faz presente ao longo da história como objeto de difícil compreensão, justamente por esta se demonstrar difícil, ao passo que interesses contrapostos movem a humanidade. Mas em que condições pode-se haver a busca por determinado direito em face de outrem sem a necessidade de disputa? Sem um silogismo que faça florescer a existência do contraponto vitória versus derrota?

Não há dúvidas de que qualquer embate no campo do Direito Processual leva a um inevitável desgaste de ambas as partes, mesmo que para aquela que desponta como vencedora da lide. Isso porque os conflitos, quando mal administrados, colocam as partes em uma espiral de ataques e contra-ataques, muitas vezes desnecessários, e mais do que isso, geradores de um alto grau de 


\title{
Personalidade Acadêmica Homenageada: \\ Florisbal de Souza Del'Olmo (Professor Convidado - UNICURITIBA)
}

desgaste para ambas, independentemente do resultado ao final da controvérsia. Por outro lado, há tempos vêm sendo demonstradas possibilidades de se buscar a solução de conflitos de maneira mais harmônica, em que se espera que ambas as partes possam se ver satisfeitas com o resultado final. Entretanto, quando se sai do abstrato e adentra-se no mundo real, nota-se que este não é um exercício fácil, talvez por lidar com tantos sentimentos que vão além do Direito e fazem com que se sobressaiam os comportamentos naturais dos homens. O que se percebe é uma evolução nos estudos sobre estes relacionamentos, que visam, sobretudo, contribuir para a formação de um processo mais harmonioso, ainda que este decorra de um fato indesejável ou desagradável.

Quando Rudolf Von Ihering expôs suas ideias em sua Luta Pelo Direito, o sinal que procurou deixar claro foi a da obrigatoriedade do exercício do cidadão em relação a seus direitos. Para o autor, a lide não se caracteriza pela mera prerrogativa do titular do direito em jogo, mas de uma obrigatoriedade que se perfaz em respeito ao sistema jurídico como um todo. $O$ curioso é que lhering nunca negou que o objetivo final do Direito é a busca pela paz, ainda que a única maneira de se fazer com que esta se concretize é através da luta, como pode ser observado com a seguinte passagem (IHERING, 2001. p. 25):

\begin{abstract}
O fim do direito é a paz e o meio para atingi-lo é a luta. Enquanto o direito precisar estar pronto ante a agressão da injustiça, o que ocorrerá enquanto existir o mundo, não poderá ele poupar-se da luta. A vida do direito é luta. Uma luta dos povos, do poder do Estado, das classes, dos indivíduos. Todo direito existente no mundo foi conquistado mediante a luta. Os mais importantes postulados do direito tiveram que ser primeiramente extraídos do combate contra seus oponentes e todo direito - o direito de um povo, bem como aquele de um indivíduo - pressupõe uma disposição contínua para a luta rumo a sua formação.
\end{abstract}

Esta concepção denota o pensamento que vigorava no século XIX, quando o exercício do Direito se confundia com a ideia de contenda, na medida em que só se poderia alcançar a satisfação e, em última análise, a paz através da luta. O problema é que neste sentido, sempre haverá aquela parte que verá frustrada a sua pretensão, seja de garantia de reparação de um bem jurídico lesado, seja pela sucumbência de 


\section{Personalidade Acadêmica Homenageada: \\ Florisbal de Souza Del'Olmo (Professor Convidado - UNICURITIBA)}

suas teses de defesa. Vale destacar que Ihering não restringe a luta pelo Direito ao âmbito processual, na proporção em que a relação entre o povo e o Estado já é capaz de gerar conflitos que visam garantir determinada prerrogativa. Assim também se estabelece na relação entre Estado e o próprio indivíduo. As considerações que o autor faz, portanto, são bastante abrangentes, pois existem pólos diversos que figuram no que chama de "labor contínuo" que se perfaz em forma de combate incessante e necessário. Ademais, é importante que se saiba que a dicotomia entre Direito objetivo e Direito subjetivo neste contexto também se faz presente, entendendo-se que o objetivo é aquele em que se manifesta na criação de normas aplicáveis no ordenamento jurídico, enquanto o subjetivo refere-se à aplicação da norma em abstrato no caso concreto. É fundamental este entendimento para que se note que, embora exista luta em ambas as perspectivas, estas possuem vieses distintos, pois enquanto a primeira refere-se à construção de direitos, a segunda demonstra ser a constante batalha para a manutenção dos mesmos, sendo que por trás de todo esse mecanismo existe sempre a mesma palavra-chave: interesses. $O$ Direito, portanto, existe em função da defesa de interesses, mas estes, por serem contrapostos, acabam por entrarem em conflito, pois partes diferentes anseiam por coisas diferentes. Aí é que surgem as desavenças, tão íntimas do Direito, que fazem com que este seja interpretado como o espaço em que há constante competição. $\mathrm{E}$ que consequentemente leva à ideia de justiça.

Fazendo uma correlação entre justiça e paz, Hans Kelsen assim falou (KELSEN, 2016. p. 19):

A justiça é uma ideia irracional. Por mais indispensável que seja para a volição e a ação do homem, não está sujeita à cognição. Considerada a partir da perspectiva da cognição racional, existem apenas interesses e, consequentemente, conflitos de interesses. Sua solução pode ser alcançada por uma ordem que satisfaça um interesse em detrimento de outro ou que busque alcançar compromissos entre interesses opostos. Que apenas uma dessas ordens seja justa, não é algo que possa ser estabelecido pela cognição racional. Tal cognição pode apenas entender uma ordem positiva evidenciada por atos determinadas objetivamente. Essa ordem é o direito positivo. 


\title{
Personalidade Acadêmica Homenageada: \\ Florisbal de Souza Del'Olmo (Professor Convidado - UNICURITIBA)
}

A importância desse conceito que permeia a Teoria Pura do Direito de Kelsen, para o tema aqui proposto, reflete o distanciamento entre o Direito (visto nesta perspectiva) e demais ciências. Diante desse positivismo irredutível, a interdisciplinariedade do Direito com outras ciências perde espaço, dificultando assim, outras medidas possíveis para soluções de conflitos dentro do próprio Direito, pois a sua teoria não se preocupa com aquilo que é justo ou injusto, e sim com o que o ordenamento jurídico determina. Ainda assim, o autor pondera (KELSEN, 2016. p. 20):

\begin{abstract}
Somente uma ordem jurídica que não satisfaça os interesses de um em detrimento dos de outro, mas que, ao contrário, proporcione uma solução de compromissos entre interesses opostos, de modo a minimizar os possíveis atritos, possui uma expectativa de existência relativamente duradoura. Somente uma ordem de tal espécie estará em posição de assegurar a paz social em uma base relativamente permanente. E, apesar do ideal de justiça em sentido original, tal como o desenvolvimento aqui, ser razoavelmente diferente do ideal de paz, existe uma tendência definida de identificar os dois ideais, ou pelo menos de substituir o ideal de justiça pelo de paz.
\end{abstract}

Portanto, mesmo que Kelsen reconheça a possibilidade de minimização de possíveis atritos, em sua teoria a justiça não pode ser concebida como a busca pela paz. Dessa forma, não há como se entender que soluções adequadas de controvérsias possam ser a finalidade do Direito, pois este guarda como objetivo central a garantia da aplicação da norma. Assim, possíveis conflitos que possam ser dirimidos, só podem os serem pela tutela do direito positivado.

A construção doutrinária de Hans Kelsen, neste sentido choca-se com as ideias formuladas do Rudolf Ihering, pois para este último, como está se vendo, não existe Direito sem luta, sem labor, uma vez que a paz, finalidade suprema do Direito, só pode ser alcançada pelo embate entre as partes, uma vez que estas demonstram interesses divergentes. No pensamento de lhering, fica latente a determinação de que antes de que se atinja a paz, a própria deve ser posta em jogo, pois não há como a garantir sem o sacrifício que ela exige. E vai além, quando diz que não pode se eximir da luta, sem que haja a renúncia do Direito diante do qual surge a querela. Diante disso, fica evidente que para se ter a paz imediata, deve se renunciar o 


\title{
Personalidade Acadêmica Homenageada: \\ Florisbal de Souza Del'Olmo (Professor Convidado - UNICURITIBA)
}

próprio Direito, caso contrário, deve por ele lutar, momento este em que a paz estará provisoriamente suspensa, por conta do período de luta. Comprova esta reflexão quando afirma que "no primeiro caso o direito é sacrificado pela paz; no segundo a paz é sacrificada em favor do direito".

As considerações do autor acerca da luta pelo direito, entretanto, não param por aí. Uma porque o titular do direito possui a obrigação de preservá-lo perante si mesmo; outra porque além desta, ainda existe o dever dessa manutenção do direito perante a comunidade. Nesta relação entre uma e outra, Von Ihering questiona (IHERING, 2001. p. 62:

\begin{abstract}
Em erro incorremos se diante de tudo isso asseveramos que a defesa do direito concreto, quando for este ameaçado, não constitui somente um dever do respectivo sujeito do direito para consigo mesmo, como também para com a comunidade? E se reconhecemos a verdade do que acabo de indicar, ou seja, que quando defende o seu direito, o sujeito adicionalmente defende a lei e juntamente com este a ordem que é essencial à vida em comunidade, será que haverá ainda alguém que conteste que esta defesa representa, do ponto de vista da comunidade, um dever em relação a esta? Todo indivíduo que frui dos benefícios do direito deve também, de sua parte, contribuir para a manutenção do vigor e do prestígio à lei; em suma, todo indivíduo é um combatente que luta pelo direito no interesse da sociedade.
\end{abstract}

Assim, deixa claro que não se pode abrir mão da luta pelo Direito, não só por si mesmo, mas é um dever de todo o cidadão garantir que este seja preservado, fazendo isso, inclusive quando se tratar de direitos individuais seus. A coletividade clama pela defesa do Direito, pois, ao contrário, se cada um dos indivíduos for um desertor neste combate constante, a própria sociedade se verá desguarnecida, colocando em risco todo o ordenamento jurídico vigente.

Mas se for levado em consideração o propósito da vida em sociedade, outras respostas podem ser ingeridas, pois, pelo o que parece, os círculos sociais não se restringem ao Direito. E quando assim for, como levar em consideração a obrigatoriedade pela luta incessante para a manutenção da comunidade? Segundo Émile Durkheim (DURKHEIM, 2006. p. 57), a visão deve ser mais ampla: 


\section{Personalidade Acadêmica Homenageada: \\ Florisbal de Souza Del'Olmo (Professor Convidado - UNICURITIBA)}

Contudo, nem todas as condições de existência da sociedade geram disposições legais. Se as ações exigidas pelo bem-estar social não conflitassem com os interesses pessoais, poder-se-ia deixar a sua execução a cargo do egoísmo, e a interferência do Direito não seria necessária. Ou seja, não precisamos ser obrigados a preservar a vida, nem a preservar a raça, a trabalhar, nem a permutar os produtos de nosso trabalho.

Para Durkheim, portanto, nem todas as coisas devem ser vistas como componentes do ordenamento jurídico, pois algumas delas transpõem-se ao Direito. Neste prisma, não poderia, mesmo que adotando a teoria de Rudolf lhering, se falar em obrigatoriedade da luta pelo Direito, pois certas determinações são inerentes aos indivíduos, independentemente de determinação legal e do positivismo jurídico. Porém, Durkheim entra em um delicado campo de interpretação, na medida em que se sabe que determinados bens são indisponíveis, como é o caso do direito à vida. $\mathrm{A}$ discussão, portanto, demonstra um elevado grau de complexidade, pois está a se falar de liberdades individuais e interesses coletivos, não podendo, evidentemente, que um simplesmente sobrepuje o outro. A questão é, até que ponto se espera que para a manutenção do Direito, sacrifícios consideravelmente onerosos sejam irrenunciáveis? Até quanto a vontade exprimida pelo indivíduo que busca alguma satisfação em relação aos seus direitos é autêntica? Será que certas determinações individuais, ainda que buscando legitimar direitos, não são capazes de frustar o ordenamento? Outro aspecto a ser suscitado, a partir desse ponto, gira em torno de algo que anda em paralelo ao Direito, mas aparentemente não tange o Direito. Tratase da questão moral, a qual Sánchez Vázquez trata como norma moral. O autor, em sua obra denominada Ética, assim leciona (VÁZQUEZ, 2011. p. 69):

\footnotetext{
Ainda que a moral mude historicamente, e uma mesma norma moral possa apresentar um conteúdo diferente em diferentes contextos sociais, a função social da moral em seu conjunto ou de uma norma particular é a mesma: regular as ações dos indivíduos nas suas relações mútuas, ou as do indivíduo com a comunidade, visando a preservar a preservar a sociedade no seu conjunto ou, no seio dela, a integridade de um grupo social.
}

Com esta afirmação, pode-se entender que a moral também é mecanismo de preservação da sociedade, sendo, inclusive, em determinados casos, um contrapeso 


\title{
Personalidade Acadêmica Homenageada: \\ Florisbal de Souza Del'Olmo (Professor Convidado - UNICURITIBA)
}

à utilização indevida de Direitos. Muito se têm falado em indústria do mero aborrecimento, quando o que deveria ser um mecanismo de reparação a um dano moral, vêm demonstrando ser aos olhos de muitos, uma oportunidade de obtenção de lucro por meio de ações indenizatórias. Isso, quando feito de forma pretensiosa, pode lesar a própria moral, pois adentra-se em um embate por motivações, em diversas ocasiões fúteis, mas rentáveis. E os caprichos do indivíduo podem causar sérios efeitos, pois esquece-se que do outro lado também há uma parte que de alguma forma pode sofrer consequências. O sofrimento, por sua vez, não atinge só a parte a quem se impõe um ônus, mas ao próprio agente, quando este age impulsionado por outras razões que não a sua convicção em torno de um direito que pretende defender, como afirmou Schopenhauer em sua célebre obra, O Mundo Como Vontade e Como Representação (SCHOPENHAUER, 2005. p. 463):

\begin{abstract}
Aquela veemência extrema da vontade já é em e para si, de maneira imediata, uma inesgotável fonte de sofrimento. Primeiro porque todo querer, enquanto tal, nasce da carência, portanto do sofrimento; segundo porque, através da conexão causal das coisas, a maioria das cobiças têm de permanecer impreenchíveis e a vontade é mais frequentemente contrariada que satisfeita. Em consequência, querer intenso e veemente sempre traz consigo sofrimento intenso e veemente. Pois todo sofrimento nada é senão querer insatisfeito e contrariado.
\end{abstract}

Nesta passagem, Schopenhauer não restringe as ações em busca de reparos ou de satisfações a aquelas desprovidas de moral. No entanto, mesmo as que são motivadas por razões legítimas causam sofrimento. A questão, portanto, guarda pertinência com a relevância do direito a ser tutelado por seu titular (ainda que por intermédio do Estado, no caso do exercício de direitos), pois não faz sentido que esta busca cause mais sofrimento que a própria ausência do direito, quando este exigir um desgaste exacerbado. Portanto, não está a se referir, aqui, somente ao mau uso do direito por aqueles que sobrepujam a moral, mas também se trata de exposição desnecessária do próprio bem-estar. Muita das vezes a honra legitima a busca pelos direitos, quando na verdade se esquece que ambos os lados querem salvaguardar cada um a sua. Quando isso ocorre, outros meios de solução de controvérsias podem ser eleitos, ainda que se esteja discutindo a questão em juízo. 


\section{Personalidade Acadêmica Homenageada: \\ Florisbal de Souza Del'Olmo (Professor Convidado - UNICURITIBA)}

Em Humano, Demasiado Humano, Nietzsche afirma que "muitas vezes é suficiente dar ao outro, a quem causamos um dano, a ocasião de uma boa palavra sobre nós, para the proporcionar uma satisfação pessoal, ou seja, dispor a seu bel-prazer a nosso respeito" (NIETZSCHE, 2007. p. 207). Com essa sugestão, o autor adentra também no campo do orgulho, o que, por vezes (e não poucas) movimentam as intenções dos envolvidos, por mais que seus atos motivados por tal sentimento onerem o contexto em que se encontram. Cândido poderia permanecer no Eldorado confortável em suas novas riquezas, mas para ele não faria sentido assim fazer, pois neste lugar todos os homens eram igualmente ricos. Então de nada adiantaria ter tudo aquilo e não poder se sentir mais rico que os outros homens. Preferiu se sobressair em sua terra de origem, quando fosse comparado aos demais. Durante a viagem, porém, viu-se novamente na pobreza. (VOLTAIRE, 2003. p. 85).

Sêneca trata do sábio como aquele que é virtuoso, caracterizando-se este pela escolha da vida tranquila, livre de vaidades e das injúrias (SÊNECA, 2007. p. 43), como demonstra a seguinte passagem:

\footnotetext{
Nos demais entes humanos (aqueles que não se caracterizam pela sabedoria), não prevalecem os discernimentos judicativos. Há, sim fraude, ousadia e ímpeto passional. Em suma, coisas que o sábio enumera nos moldes de ocorrências fortuitas porquanto a fortuna é que assedia de todos os lados e pressiona para o aviltamento.
}

De acordo com as afirmações acima transcritas, além daquelas situações em que ocorre um desgaste desnecessário entre as partes envolvidas em um conflito, os oportunismos e ações movidas por orgulho, ditas em defesa da honra, fazem com que proliferem querelas desmedidas, que acabam por causar um inchaço preocupante no Judiciário, aqui já trazendo para a realidade do ordenamento jurídico pátrio. E essas ações são asseguradas, como não poderia deixar de ser, pelo direito de ação e do contraditório e da ampla defesa, como não poderia deixar de ser. Aí é que entram em cena as soluções alternativas, ou talvez mais apropriadamente chamadas de adequadas, para a solução de conflitos. Não está, portanto, sendo defendido aqui o cerceamento à busca pela tutela do Estado, mas busca-se, por 


\title{
Personalidade Acadêmica Homenageada: \\ Florisbal de Souza Del'Olmo (Professor Convidado - UNICURITIBA)
}

outro lado, lembrar da existência de outros mecanismos mais apropriados para o apaziguamento e a harmonização entre as partes. E isto tem se mostrado possível, por meio de diversos métodos consensuais de resolução de controvérsias. Em determinados momentos, a criação de estratégias dentro da relação processual, como que embasadas nos trinta e oito estratagemas da dialética erística (SCHOPENHAUER, 1997), demonstra-se descabida diante da proposta de novos horizontes rumo às soluções cada vez mais pacíficas.

Obviamente que estas questões passam pelo crivo de outros fatores importantes, trazidos pelo caso concreto. Um deles parece ser o merecimento, afinal, deve-se haver o mínimo deste para que se possa ao menos, se for da vontade das partes e estiver a se tratar de direitos disponíveis, indícios de que determinado acordo tenha guarida no merecimento das partes, para que ambas saiam satisfeitas, ainda que infrutífera seja a tentativa de autocomposição.

Sobre o merecimento, Aristóteles tratou na Ética a Nicômaco (ARISTÓTELES, 2009. p. 127) da seguinte forma:

\begin{abstract}
Ora, considera-se que uma pessoa seja detentora de grandeza de alma se reivindicar muito e merecer muito; aquele que muito reivindica sem ter merecimento é tolo, e ninguém que seja moralmente virtuoso é tolo ou insensato. O homem da grandeza de alma é assim, como acabamos de descrever. Aquele que merece pouco e reivindica pouco é recatado ou comedido, mas não grandioso de alma, uma vez que isso envolve grandeza tal como a beleza envolve tamanho. Aquele que reivindica muito, mas não é merecedor de muito, é vaidoso, embora nem todos que reivindicam mais do que merecem sejam vaidosos. Aquele que reivindica menos do que merece é pequeno de alma, quer seus méritos sejam grandes, quer sejam moderados, ou mesmo que mereça pouco se reivindicar ainda menos.
\end{abstract}

Obviamente que as afirmações de Aristóteles, se contextualizadas, devem sofrer uma relativização. Mas a importância de se entender que outros elementos, tal como o merecimento, também integram as relações processuais que nascem e que podem, de acordo com a natureza da lide no caso concreto, ser tratadas de uma forma ou de outra. Resolvidas de maneiras drásticas, ou através da celebração da paz. 


\title{
Personalidade Acadêmica Homenageada: \\ Florisbal de Souza Del'Olmo (Professor Convidado - UNICURITIBA)
}

Por fim, compreende-se como valiosa a contribuição de Cícero em torno da justiça e do indivíduo virtuoso (CÍCERO, 2008. p. 47):

\begin{abstract}
Das três remanescentes virtudes, a mais abrangente é a que abarca a socialidade dos homens entre eles e ávida em comunidade. As suas fontes são duas. Primeiro, a justiça em cujo fulgor a virtude esplende ao máximo. É por ela que os homens denominam-se pessoas de bem. A ela se une a beneficiência também chamada de benignidade ou liberalidade. $O$ primeiro dever da justiça edita não prejudicar ninguém, salvante o caso de provocação injuriosa; depois, manda usar das coisas coletivas como comuns e as particulares como próprias.
\end{abstract}

Desta maneira, encerra-se a proposta até aqui aventada, que é a de demonstrar a possibilidade de se buscar soluções para a paz por meio do consenso, deixando para que as desavenças a serem resolvidas por meio do contencioso ocorram quando forem estas inevitáveis. Resta agora expor algumas das possibilidades de soluções adequadas de controvérsias.

\section{MEIOS ADEQUADOS DE SOLUÇÃO DE CONFLITOS}

$\mathrm{Na}$ interpretação do Novo Código de Processo Civil, chama a atenção, levando-se em conta a proposta do presente estudo, um dispositivo em especial. Trata-se do artigo 334, que assim prevê:

\begin{abstract}
Art. 334 - Se a petição inicial preencher os requisitos essenciais e não for o caso de improcedência liminar do pedido, o juiz designará audiência de conciliação ou de mediação com antecedência mínima de 30 (trinta) dias, devendo ser citado o réu com pelo menos 20 (vinte) dias de antecedência. $\S$ 4ํำ A audiência não será realizada: I - se ambas as partes manifestarem, expressamente, desinteresse na composição consensual; II - quando não se admitir a autocomposição.
\end{abstract}

A inclusão deste dispositivo pelo legislador é motivo de comemoração por parte de todos aqueles que veem com entusiasmo a consolidação de medidas que visam contribuir com o bom andamento dos processos e consequentemente com a otimização do Poder Judiciário. Mas não só por isso. Comemora-se a disponibilidade, 


\section{Personalidade Acadêmica Homenageada: \\ Florisbal de Souza Del'Olmo (Professor Convidado - UNICURITIBA)}

em lei, de novas técnicas para a solução alternativa de conflitos. Quando se possibilita às partes a resolução da controvérsia em sede de autocomposição, está na verdade a se premiar a liberdade das partes, que possuem a prerrogativa de celebrarem, conforme a manifestação de vontade destas, negócios processuais, sinalizando que o Direito Processual também evolui e que este pode-se valer do bom entendimento entre as partes. Algumas considerações devem ser feitas acerca do caput do artigo supramencionado, assim como em seu $\S 4^{\circ}$ e incisos. Primeiramente, cumpridos os requisitos da petição inicial, o juiz deve designar audiência de conciliação ou mediação. O que se nota é que não se trata de uma faculdade dada ao magistrado, e sim de uma obrigatoriedade de designação de audiência conciliatória, nos moldes dos parágrafos do mesmo dispositivo. Em segundo lugar, o $\S 4^{\circ}$ prevê, no inciso $\mathrm{I}$, que as partes podem demonstrar desinteresse na autocomposição, devendo, para tanto, manifestarem-se no processo neste sentido. E ainda, conforme previsão do inciso II, quando esta não couber, o que ocorre, em suma, quando se tratarem de direitos indisponíveis. O importante é notar o quanto as partes ganham com a possibilidade tentarem, em juízo, a realização de acordo. Aqui reside um fator muito importante. As partes, por óbvio, não estão compelidas a realizarem acordo, pois senão não teria natureza de acordo, mas de decisão. No entanto, ainda que não cheguem a um consenso, a satisfação de ambas é alcançada no sentido de que puderam se manifestar no processo em sede de conciliação. Por outro lado, a celebração de acordo é a manifestação clara de que o Direito Processual não se confunde com lide, ou seja, que o contencioso não presume o exercício do Direito. Pelo contrário, o legislador deixou claro que, sempre que possível, as partes gozarão da possibilidade de ver as suas vontades satisfeitas. $\mathrm{Na}$ via conciliatória, ao invés de haver confronto, há a colaboração entre as partes. Nesse sentido, Fernanda Tartuce explica (TARTUCE, 2016. p. 80):

A lógica consensual (coexistencial ou conciliatória) é aplicada em um ambiente onde a pauta é colaborativa: as pessoas se dispõem a dialogar sobre a controvérsia e a abordagem não é centrada apenas no passado, mas inclui o futuro como perspectiva a ser considerada. Por prevalecer a autonomia dos envolvidos, o terceiro facilitador da comunicação não 


\section{Personalidade Acadêmica Homenageada:}

Florisbal de Souza Del'Olmo (Professor Convidado - UNICURITIBA)

intervém para decidir sobre o mérito, mas para viabilizar o diálogo em prol de resultados positivos.

Muito importante atentar-se para alguns detalhes. A autora deixa claro que 0 que se busca não é necessariamente o acordo, mas o diálogo entre as partes. Dessa forma, a conciliação demonstra a colaboração entre as partes, fator esse fundamental para que a audiência conciliatória tenha o seu devido valor, ainda que infrutífera, pois, mais uma vez, afirma-se que a intenção é fazer com que as partes manifestem as suas vontades para que eventualmente cheguem a um consenso. O conciliador, por sua vez, mantém-se na posição de facilitador, não interferindo na vontade das partes. A sua presença, ainda que não esteja presente para opinar, é fundamental, porque, além de presença obrigatória, é ele quem detém as técnicas de condução das audiências de conciliação, devendo intervir somente naquilo que the couber.

Vale a pena fazer um breve destaque à realidade hoje no ordenamento jurídico brasileiro e como os Tribunais têm lidado com a determinação do artigo 334 do Novo Código de Processo Civil. Pode-se ver com otimismo, embora as metas ainda estejam aquém do ideal dentro da proposta das negociações processuais e das conciliações entre as partes envolvidas no processo. Isso porque o que se têm visto é um grande esforço para que a conciliação se torne uma realidade em todo o território nacional. O Conselho Nacional de Justiça vem incentivando os Tribunais, os quais se responsabilização pelas aplicações dos centros de conciliação judiciais e também pelas capacitações e formações de conciliadores, a levarem para dentro de suas estruturas e consequentemente para a sociedade, os métodos de solução alternativa de conflitos. No âmbito da Justiça Estadual, os Tribunais são responsáveis pela criação dos CEJUSCs, que são exatamente estes centros de conciliação a serem levados às comarcas sob a jurisdição de cada um destes. Os Tribunais possuem liberdade para criarem políticas de inclusão e mobilização dos meios alternativos, como os mutirões que têm acontecido em todo o Brasil e a Justiça itinerante, que leva às comunidades menos favorecidas os núcleos de conciliação, como acontece nas regiões ribeirinhas. Na Justiça Federal não tem sido diferente. Os CEJUSCONs, como são denominados, contam com juízes coordenadores, que ficam responsáveis 


\section{Personalidade Acadêmica Homenageada: \\ Florisbal de Souza Del'Olmo (Professor Convidado - UNICURITIBA)}

pelas conciliações, o que gera agilidade processual, uma vez que o juízo de origem remete os autos ao CEJUSCON indicado para que lá se proceda a devida conciliação. Dessa forma, o juiz coordenador do núcleo de conciliação pode, ele mesmo, homologar o acordo que venha a ocorrer. Caso a conciliação seja infrutífera, os autos retornam ao juízo de origem.

Isso é como tem sido promovido na esfera judicial. No entanto, há outro incentivo em voga, que é a solução de conflitos em âmbito extrajudicial, o que se dá, basicamente pela realização de mediações de conflitos por profissionais inclusive de áreas alheias às formações jurídicas. É o caso da comunidade da psicologia, que tem buscado participar de forma ativa, com a presença ou não de operadores do Direito, o que pode gerar estranhamento por parte destes. No entanto, a recomendação é para que aquelas pessoas que queiram participar de processos de mediação façam após a realização de cursos de formação de mediadores, ainda que a Lei da Mediação (Lei 13.140/15) assim não exija, tampouco que o mediador detenha formação jurídica. Conta-se, porém, com a responsabilidade de todos os envolvidos, acreditando-se que eventuais dúvidas sejam dirimidas por peritos das áreas que assim demandarem.

Existem, porém, diferenças entre a conciliação e a mediação. Que vão além do fato de, de modo geral, uma ser judicial e outra extrajudicial. Luiz Antonio Scavone Junior explica que (SCAVONE JUNIOR, 2016. p. 273):

\footnotetext{
É preciso observar que a mediação é sempre voluntária, a teor do $\S 2^{\circ}$, do artigo $2^{\circ}$, da Lei $13.140 / 15$, segundo o qual 'ninguém será obrigado a permanecer em procedimento de mediação'. A participação da conciliação, contudo, pode ser compulsória, notadamente na modalidade judicial, nos termos do artigo 334 do CPC, que impõe ao juiz a determinação de audiência. A transação é o resultado da mediação e da conciliação que atingiram o seu objetivo: o consenso entre os contendores.
}

Sabe-se que, embora 0 autor, na transcrição acima tenha falado em conciliação compulsória, esta ocorrerá se as partes não transigirem sobre a realização ou não, manifestando-se para tanto nos autos processuais, conforme preconiza o $\S 4^{\circ}$ do artigo 334 , como já mencionado. O importante aqui é salientar a 


\section{Personalidade Acadêmica Homenageada:}

Florisbal de Souza Del'Olmo (Professor Convidado - UNICURITIBA)

possibilidade de realização do acordo extrajudicialmente com o auxílio, de modo geral, de um mediador. Importante salientar que, em regra, judicialmente se têm conciliadores e extrajudicialmente, mediadores. No entanto, pode haver a presença de um ou de outro nas duas esferas, de acordo com as prerrogativas legais de cada um desses agentes, o que ocorre excepcionalmente.

Outro mecanismo extrajudicial que também configura solução alternativa de conflitos é a amplamente difundida, especialmente em outros ordenamentos jurídicos, como nos Estados Unidos da América, em que é muito comum, é o instituto da Arbitragem, disciplinada pela Lei no 13.129/15, que é amplamente discutida na doutrina nacional e no Direito comparado. No entanto, para efeitos do presente estudo, cumpre citá-la pela sua importância, mas não haverá aqui exposição sobre a sua constituição e suas características, porém o registro é necessário.

Outros mecanismos estão em expansão no Brasil, como é o caso da Justiça Restaurativa, na esfera penal, das Constelações Familiares e Sistêmicas, sobretudo no Direito de Família e a Comunicação Não Violenta. Todos estes são métodos alternativos de conflitos, ou métodos adequados, como também são chamados. Portanto, como destaca Enia Cecília Briquet, existem diversos processos de Resolução Alternativa de Disputas (RDA) (BRIQUET, 2016. p. 16), estando estes à disposição da sociedade na busca pelas melhores escolhas para a harmonização e o apaziguamento de controvérsias.

\section{CONCLUSÃO}

Diante das considerações feitas ao longo do estudo, pôde ser observado que é mais do que natural que a tendência é de se olhar para uma controvérsia com a concepção de disputa. O tempo demonstra que dentro do estudo do Direito, sobretudo pelos positivistas, a vinculação entre necessidade de luta e garantia de direitos andam juntas, uma completando a outra. No entanto, mesmo em tempos mais remotos, pensadores de fora do Direito já reconheciam que não 


\section{Personalidade Acadêmica Homenageada:}

Florisbal de Souza Del'Olmo (Professor Convidado - UNICURITIBA)

necessariamente estas prerrogativas têm que ser conjugadas. Ao contrário, uma vida tranquila pressupõe a ausência de querela, mesmo que o indivíduo se importe em garantir os seus direitos.

Para que esta concepção ganhasse força dentro do Direito, novas tendências passaram a ser válidas na busca pela satisfação dos interesses de partes que venham a manifestar suas vontades, seja judicial ou extrajudicialmente. Crê-se que esteja cada vez mais claro que isto não só é possível, e mais do que isso, que tem se demonstrado uma tendência em vários ordenamentos jurídicos rumo à solução adequada de conflitos.

\section{REFERÊNCIAS}

ARISTÓTELES. Ética a Nicômaco. Bauru: Edipro, 2009.

BRIQUET, Enia Cecília. Manual de Mediação: teoria e prática na formação do mediador. Petrópolis: Vozes, 2016.

DURKHEIM, Émile. Ética e Sociologia da Moral. São Paulo: Landy, 2006.

HICKS, C. Scot, HICKS, David V. O Guia do Imperador. São Paulo: Planeta, 2007.

IHERING, Rudolf Von. A Luta Pelo Direito. Bauru: Edipro, 2001.

KELSEN, Hans. Teoria Geral do Direito e Teoria Geral do Estado. São Paulo: Martins Fontes, 2016.

NIETZSCHE, Friederich. Humano, Demasiado Humano. São Paulo: Escala, 2007.

SCAVONE JUNIOR, Luiz Antonio. Manual de Arbitragem, Mediação e Conciliação. Rio de Janeiro: Forense, 2016.

SCHOPENHAUER. Como vencer um debate sem precisar ter razão. Rio de Janeiro: Topbook, 1997.

TARTUCE, Fernanda. Mediação nos Conflitos Civis. São Paulo: Método, 2016.

VÁZQUEZ, Adolfo Sánchez. Ética. Rio de Janeiro: Civilização Brasileira, 2011.

VOLTAIRE. Cândido. São Paulo: Martins Fontes, 2003. 